INTERNATIONAL DESIGN CONFERENCE - DESIGN 2018

https://doi.org/10.21278/idc.2018.0198

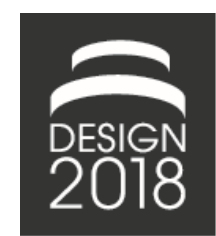

\title{
EXPECTED VS. REAL EFFECTS OF AGILE DEVELOPMENT OF PHYSICAL PRODUCTS: APPORTIONING THE HYPE
}

\author{
T. S. Schmidt, S. Weiss and K. Paetzold
}

\begin{abstract}
Agile development of physical products is on the rise. But can it live up to its promise? This study investigates and opposes expected (reasons for adopting) and actual effects (real value) of agile development specifically of physical products. By conducting an online survey, it turns out that primarily improvements in soft factors like communication, reaction time to changes, transparency and flexibility are associated with agile development. It has less positive effects on hard controlling KPI's such as project lead time or costs. A means-end analysis helps to explain why.
\end{abstract}

Keywords: product development, design management, engineering design, VUCA, hype cycle

\section{Introduction}

Volatile, uncertain, complex and ambiguous (VUCA) environments are not solely a phenomenon in software development. Typical drivers of VUCA environments are customers that cannot specify what the product should look like, emerging technologies, dynamic competitors and manifold design constraints e.g. resulting from platform strategies. VUCA environments lead to the fact that it is impossible to foresee all actions to be taken, resources needed, risks to be observed etc. for a development project. Thus, traditional product development that follows an upfront-defined project plan is likely to fail under such circumstances (Schmidt and Paetzold, 2016).

This is why agile development approaches are gaining increasing momentum in the last decades (Dingsøyr et al., 2012; Version One, 2016; Komus and Kuberg, 2017; Schmidt et al., 2018). Once manifested for and in the software industry (Beck et al., 2001), agile development becomes more and more interesting for the development of physical products (Schmidt et al., 2018). Physical products are products that do not consist of software only. Thus, they have at least to some extent a physical, tangible character. Such products can be mechatronical or cyber physical products that are in need of mechanical, electrical and software engineering as well as other disciplines such as medicine, physics or chemistry (e.g. consumer electronics, production machines or medical devices).

Interestingly, there is a gap in the understanding of agile development between academia and practice. Academia defines agile development as an ability of the project team. "Agility is the capability to react, and adopt to expected and unexpected changes within a dynamic environment constantly and quickly; and to use those changes (if possible) as an advantage." (Böhmer et al., 2015, p. 6) Similarly, Conboy (2009, p. 340) accumulates popular definitions from software development: Agility is "the continual readiness of an ISD (information system development) method to rapidly or inherently create change, proactively or reactively embrace change, and learn from change while contributing to perceived 
customer value (economy, quality, and simplicity), through its collective components and relationships with its environment."

However, talking and listening to the industry and their reasons why they want to implement agile development approaches reveals that they want to develop cheaper and quicker. According to a survey of We.Conect (2016) among the participants of the Agile Pep Minds'16 Conference in Berlin, Germany, that focuses on agile development of physical products only, reducing the time-to-market is the most important motivation to become more agile. Out of 178 survey participants $65 \%$ voted for that. The book title "Scrum: The art of doing twice the work in half the time" (Sutherland, 2014), which is a very popular reference among consultants and corporate level managers, puts a fine point on it. This, however, is not part of the academic discussion. The academic understanding of agility does not refer to shorter project lead times, nor reduced development costs. Agility in science is rather a special case of changeability (Schmidt et al., 2016) that comes at a cost and, hence, impacts project costs and lead times rather negatively.

Obviously, a discrepancy between the academic understanding of agile development and the motivations why industry wants to implement agile development exists. Analogously to agile software development, agile development of physical products might be hyped, too (Janes and Succi, 2012). Inflated expectations will cause frustration when it becomes obvious that the used approach cannot achieve various expectations (Gartner, 2017). Realising that, the study at hand aims at bringing light into the before mentioned discrepancy. For that, we want to contrast expected effects before implementation with real effects of agile development in practice. While expected effects refer to the motivations why companies want to get more agile in their product development, real effects reflect what the company will indeed obtain after the implementation. The deviation between expected and real effects might help to explain the hype. Thus, we want to answer following research questions:

RQ1: What are the expected effects of agile development of physical products in practice?

RQ2: What are the real effects of agile development of physical products in practice?

RQ3: Is agile development of physical products hyped, and in which aspects?

\section{State of the art: The value of agile development in the academic discourse}

Agile development approaches originate from the American software industry. It can be seen as a countermovement to single-loop learning, optimization-oriented and inflexible development projects (Nerur and Balijepally, 2007). Instead of focusing on formal, bureaucratic processes that are assumed to require command and control, agile development centres the developers as human beings (Nerur et al., 2005). While traditional product development, which is often associated with waterfall or stage-gate processes (Cooper, 2014; Chuang et al., 2014), favours cooperation, specialists and decision making through experts, agile development tends to decentralized decision making, collaboration, shared ownership and fast trail-and-error loops (Nerur et al., 2005; Nerur and Balijepally, 2007). Agile development is about learning and knowledge creation through real life experimentations that lead to frequent small, testable releases (Menold et al., 2016; Hostettler and Böhmer, 2017). Mistakes are ok and are considered a chance to learn and improve. Traditional product development, however, usually tries to hit the right product with the first prototype (Nerur and Balijepally, 2007). Mistakes are perceived as failures that someone has to take responsibility for (Nerur and Balijepally, 2007).

Predominately, agile development is a mindset that makes sure that project staff is motivated and committed to be sensible about changing project circumstances (Beck, 2000). In this way, the team can be very responsive and quick in terms of the reaction time. They try to utilize arising changes (like new technology, new market opportunities, new competitors) as advantage (Böhmer et al., 2015). This way of thinking is written down in the Manifesto of Agile Software Development (Beck et al., 2001). Socalled agile methods like Scrum, Kanban or Design Thinking provide sets of practices and organizational frameworks to give (semi-)structured guidance in acting according to the required mindset. 
Janes and Succi (2012) argue that agile software development as a new methodical idea follows Gartner's Hype Cycle (Gartner, 2017). Firstly, the new idea gets visible rapidly and expectations of the relatively new concept rise. Secondly, these high expectations turn out to be partially not realistic so that increasingly more people abandon to try something else. The visibility and expectations diminish to a minimum, which Gartner calls the trough of disillusionment. Some people keep believing in it and develop it further. The concept becomes mature, reliable and rich in details. This, in turn, increases the visibility again on the slope of enlightenment that leads to the plateau of productivity (compare Figure 4). Derived by a Google Trends analysis, agile software development was in the trough of disillusionment in 2012: "Agile Methods passed the peak of inflated expectations, the hype is over." (Janes and Succi, 2012, p. 217) In the meanwhile, agile development has become a standard approach for software development projects (Version One, 2016; Komus and Kuberg, 2017).

The benefit of agile development has been investigated in software development by Version One (2016) and Rodríguez et al. (2012). Both differentiate between expected and real effects. Version One (2016) focuses primarily on the North American software industry and investigates agile development only, while Rodríguez et al. (2012), however, limit themselves to Finland and mix agile and lean development. Both studies are mostly in line. Increasing productivity, reducing project lead times, improving software quality and advancing flexibility are among the top five reasons why companies try to implement agile development. In contrast, improved team communication, increased productivity and improved ability to manage changes are among the top four actual improvements.

For agile organizations, that matters especially for scaling agile development approaches, Komus and Kuberg (2017) provide well-founded empirical numbers with yearly large-scale surveys (n>900). According to Komus and Kuberg (2017), optimizing time-to-market (61\%), optimizing product quality $(47 \%)$, reducing project risks $(42 \%)$ and optimizing team morale $(40 \%)$ are the most chosen reasons why companies want to become more agile in general. $73 \%$ of the participants claim that agile development has improved the companies output and efficiency (12\% no improvement, $15 \%$ N/A). Nevertheless, Komus and Kuberg (2017) do not go into a detailed analysis of real effects.

In agile development of physical products, We.Conect (2016) conducted a survey among their clients and participants of the conference Agile Pep Minds'16. This conference is one of the largest industryrelated conferences on agile development specifically of physical products in German-speaking countries. The survey reports that accelerating development processes $(65 \%)$, improving transparency $(54 \%)$ and increasing productivity $(42 \%)$ are the top three motivations to apply agile methods. It is questionable, if the survey can meet scientific quality demands as results can potentially collide with their company's interest to market their conference (Agile Pep Minds). However, it provides a first indication on the pattern of opinions in agile hardware development. Similar to Komus and Kuberg (2017), We.Conect (2016) does not cover actual benefits.

Based on our literature review, there is no study available, which scientifically investigates the benefits and empirically opposes expected with real effects of agile development specifically for the development of physical products. Thus, it remains open, if and - if yes - why there exists a gap between expected and real effects of agile hardware development. This is the object of the study at hand.

\section{Research approach to answer the research questions}

To answer the research questions we set up an online survey by using Survey Monkey (www.surveymonkey.com). By means of an online survey we expected to obtain more answers compared with personal interviews (e.g. via telephone), but sufficient context details by also asking company-related questions. In order to reduce cultural differences we limited the area of interest to German-speaking countries, namely Germany, Austria and Switzerland. Consequently, we set up the survey in German to minimize the fuzziness of translations.

Among 40 questions that we asked in the survey (see Schmidt et al. (2018) for all questions and answers), two questions matter for the study at hand:

1. Question \#22: "Please think back to the time before implementing agile development approaches in your company. Which value did you or your company expect from agile approaches?" 
2. Question \#35: "Please put yourself in the time after implementation of agile development approaches in your company (even if this time is possibly in the future). Which value does really arise through agile approaches in your company?"

For both questions, we presented the same set of answers consisting of 24 partial values (see Figure 1 or Figure 2). To make the results comparable to other surveys in other fields of application (e.g. Komus and Kuberg (2017) for agile organizations, Version One (2016) for agile software development), we decided to construct the partial values accordingly. We excluded some that we thought might be less relevant for agile development of physical products and included some new ones. In addition, we randomized the order of partial values for each participant to minimize our influence on the participants' answers. Figure 1 and Figure 2 contain all 24 partial values we asked in the survey.

The participants should evaluate each partial value on a 5-point Likert scale plus a N/A option (6 answer possibilities in total) according to their experience. 0 represents "no value expected/indeed" and 4 stands for "very high value expected/indeed".

For publishing, we used three channels. Firstly, we send out a short description of the motivation and goal of the study including a link to the survey as part of the monthly VDI Email Newsletter. VDI (Verein Deutscher Ingenieure) as the Association of German Engineers represents the interest of engineers in Germany and has more than 150.000 members. We reached about 45.000 of them twice (invitation and reminder). Secondly, we posted a short description and a public link on Xing and LinkedIn. Thirdly, we used personalized emails to send out survey invitations to about 700 developers we know of. Consequently, the risk of biased results due to too narrow participant selection is marginal.

In total 228 persons from about the same number of different companies participated in the survey. As beginners (those who just started with agile development) probably cannot evaluate the real effects due to less experience, question \#35 was visible only for those who said in question \#34 their implementation status of agile development is "midcourse", "advanced" or "completed" (on a scale of "not started", "started", "midcourse", "advanced", "completed" and "N/A"). 150 of 228 participants answered question \#22 (expected value) and 61 of 228 participants answered additionally question \#35 (real value).

\section{Survey results}

Figure 1 and Figure 2 summarize the answers of question \#22 and \#35. The graphs represent the means of each partial value among all participants and displays the corresponding delta between the expected value mean and the real value mean.

For the expected value of agile development, Figure 1 and Figure 2 include ratings of question \#22 only for beginners ("not yet started", "started" or "N/A" implementation progress) as experts could be biased by the real effects. Survey participants that are not interested in implementing agile development of physical products in their companies are excluded. 150 of 228 participants answered question \#22, 83 of them are beginners.

For the real value, Figure 1 and Figure 2 consider only those participants that claim a "midcourse", "advanced" or "completed" implementation status of agile development in their companies. In other terms, we excluded beginners that have less experience with real effects. In total, the real value graph in Figure 1 and Figure 2 base on 61 participants (that are also incorporated in the expected value graph).

Some participants used the N/A answer option for only some values. We removed those single value ratings (not the remaining ratings of the participant) and adapted the total number of participant for the corresponding value to avoid biased means.

On the one hand, Figure 1 shows that aspects like transparency, learning and knowledge creation and alignment of the product to company strategies are underestimated. Agile development has indeed a higher benefit on those dimensions than expected. In contrast to that, aspects like shortening project lead times, improving adherence to time schedule, reducing development costs and higher productivity 
within the development project are overestimated. Hence, agile development does provide a lower benefit on those dimensions than expected.

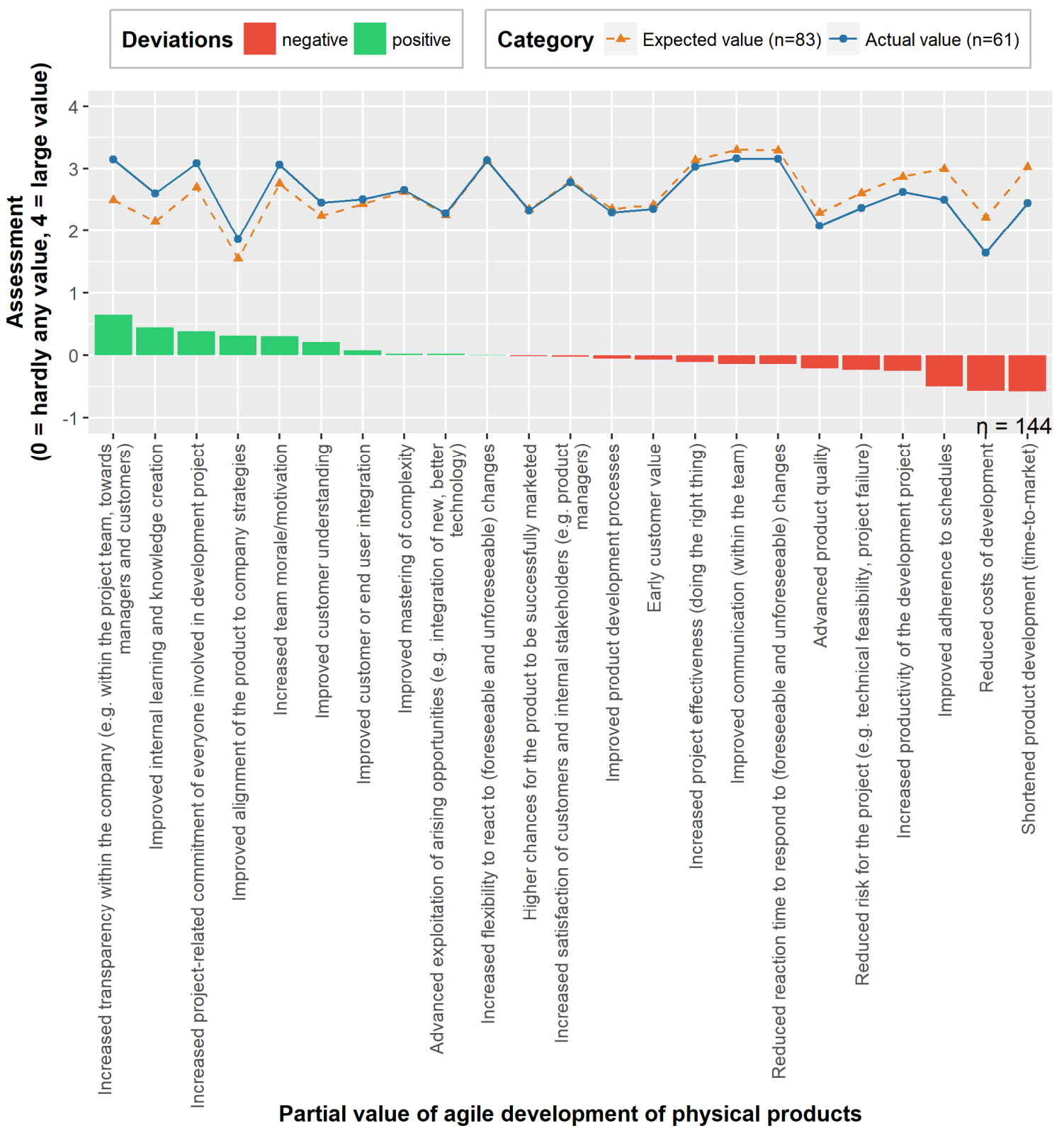

Figure 1. Expected vs. real value of agile hardware development - sorted by the delta

On the other hand, Figure 1 can be analysed concerning the absolute numbers, which is presented in Figure 2. The highest real value through agile development is improved communication, followed by higher reaction time to changes, improved transparency, higher flexibility, higher project commitment and increased team morale. Those are soft aspects that are difficult to measure and usually not monitored in companies. However, the lowest real value in agile development is reduced development costs, improved alignment of the product to company strategies and improved product quality. They are part of the hard, relatively well-measurable controlling key performance indices (KPI's) of most companies. 


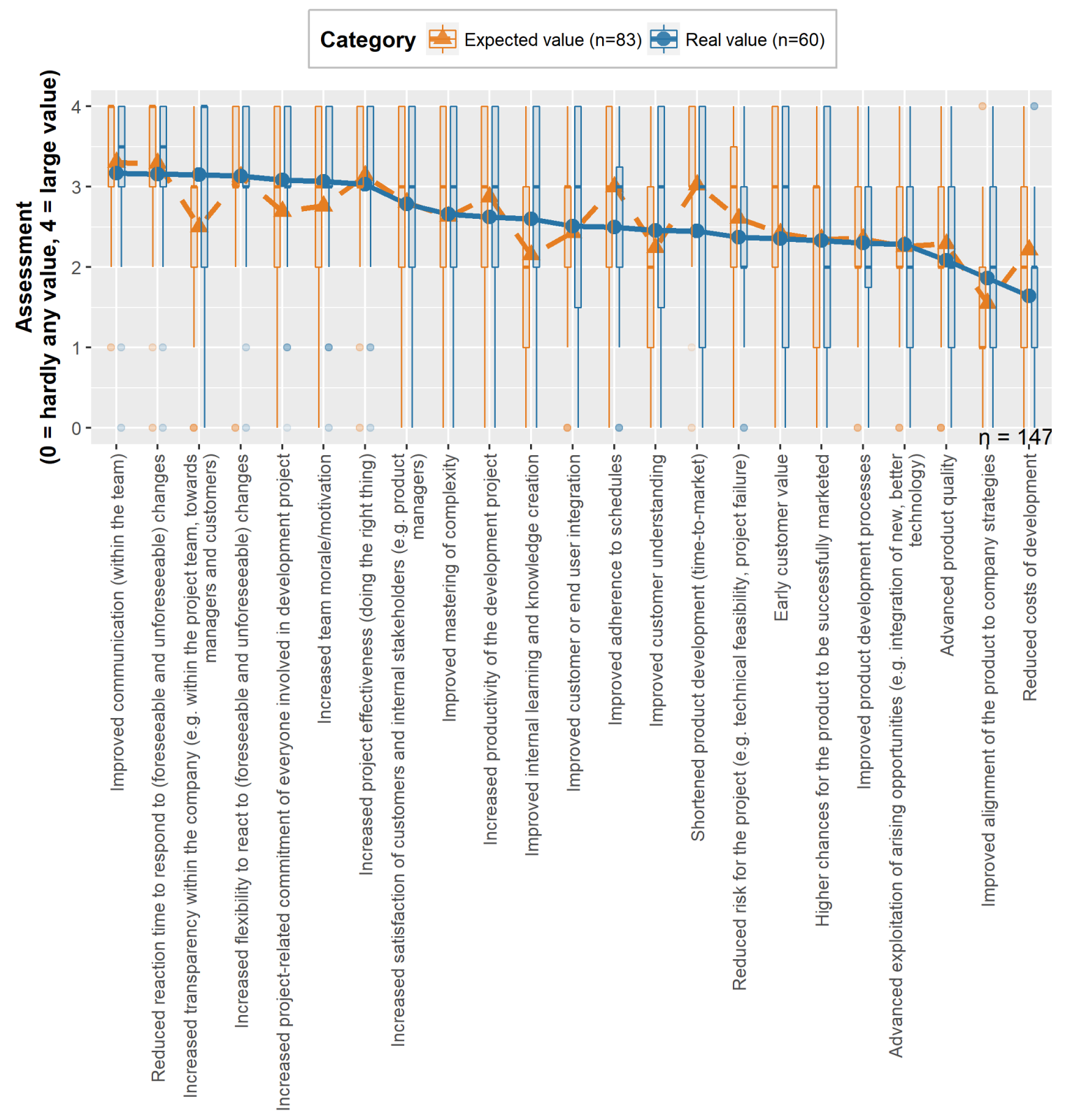

Partial value of agile development of physical products

Figure 2. Expected vs. real value of agile hardware development as box plot - sorted by the real value

Furthermore, when it comes to the highest expected value through agile development, the survey reveals the following: Participants hope to improve team communication, reaction time to changes, flexibility, project effectiveness and adherence to time schedule. In contrast to that, they do desire less benefit through agile development in alignment of the product to company strategies, reduced development costs and utilization of arising opportunities.

In essence, it turns out that agile development has positive effects particularly on soft factors like transparency, communication and commitment and less positive effects on hard controlling KPI's like costs, time and quality. Why is that? 


\section{An attempt to explain the survey results}

While analysing the results, an explaining hypothesis evolved:

Agile developed has immediate positive effects on soft factors in product development projects, but they can contribute to hard controlling KPI's on several means-end instances.

To test that hypothesis we conducted a workshop during the Agile Pep Minds'17 Conference in Berlin. This conference targets at practitioners of agile development specifically of physical products from Germany, Austria and Switzerland. Among more than 200 conference participants 95\% of them are decision-makers in their companies and $69 \%$ are in charge of budgets larger than $1 \mathrm{~m} €$ (We.Conect, 2017). The conference organizers thankfully let us utilize a world café session for that workshop.

\subsection{Workshop design}

In four iterations à $30 \mathrm{~min}$, the conference participants moved from one world café workshop to another in a pre-defined manner. In each iteration, 6 to 15 persons took part in our workshop to test the hypothesis. The iterations were held separately so that the participants of the following iteration do not see and get influenced by the results of previous iterations. This minimized the risk of biased results.

Firstly, we explained the Gartner Hype Cycle and displayed it on a sheet of paper attached to a wall. We asked the workshop participants to position (a) the agile software development and (b) the agile development of physical products in the Hype Cycle with small stickers in two colours.

Secondly, we split the workshop participants in two groups and provided the partial values from the survey (compare Figure 1 or Figure 2) plus some general business values (like "Increases commercial profits") on small cards for each of the groups. In two means-end diagrams, they were asked to position as much of those cards as possible within $10 \mathrm{~min}$ according to their experience.

The means-end diagram ranks partial values according to their goals and intermediate steps. For instance, "Improved transparency within the company" could be a means to the end "Improved internal learning processes and knowledge creation" which again could be a means to the end "Improved stakeholder satisfaction". Following this logic, the means-end diagram displays means-end relationships between the cards. While there was a starting point given as "Acting according to the values and principles of the agile manifesto", we did not pre-define any ending point.

Finally, we wrapped up the iteration's results and explained our hypothesis to be tested. We took pictures of the rated Gartner Hype Cycle and the means-end diagrams of both groups. After cleaning the diagrams (to avoid influencing the participants of following iteration with the results of previous iteration), we started over again with another group.

\subsection{Workshop results}

As a result, participants of all iterations consistently ranked soft aspects like transparency, communication and commitment on the lowest level (first and second means-end instance after acting according to the agile manifesto). Although we did not provide any ending point, "Increasing commercial profits" was rated as the highest level in almost all cases. Concerning the other hard controlling KPI's, no group positioned "Shortening time-to-market" or "Reducing costs" at low levels.

Of course, some differences existed between the groups. Some, for instance, created distinct levels with multiple cards on each given level, while others built paths with rich nuances. In terms of the content, however, the general trend was surprisingly consistent (see Figure 3): While hard controlling KPI's were positioned at the top, acting according to the agile manifesto is an immediate means to an end of soft aspects like communication and transparency especially. Thus, the workshop confirms the above hypothesis. Agile development directly improves soft aspects of product development products that contributes - but not necessarily - to hard controlling KPI's on several means-end instances. 


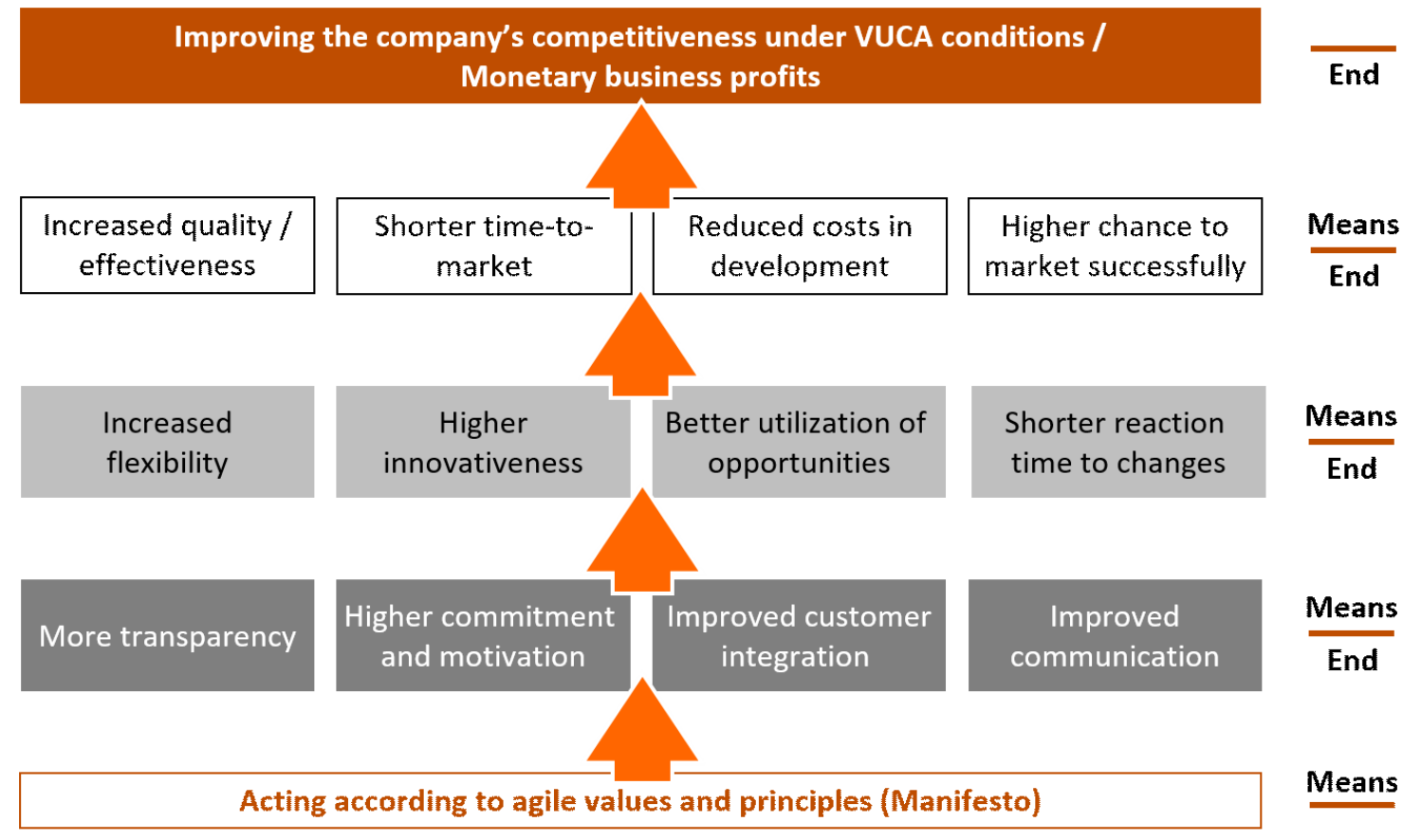

Figure 3. Means-end diagram aggregated from all groups

Concerning the Gartner Hype Cycle, the ratings among the iterations were very similar again. Figure 4 summarizes the areas, in which stickers were attached, and their average positions per iteration. On the one hand, agile development of physical products seems to be on the rise and it has not reached the disillusion phase, yet. On the other hand, the participants think that agile software development has definitely passed the trough of disillusion already and is somewhere on the slope of enlightenment. When it comes to the time scale of the Gartner Hype Cycle, the participants thought that agile software development is about 9 to 15 years ahead. However, some participants argued that agile development of physical products might pass the Hype Cycle faster since it is possible to learn from the experiences made in agile software development.

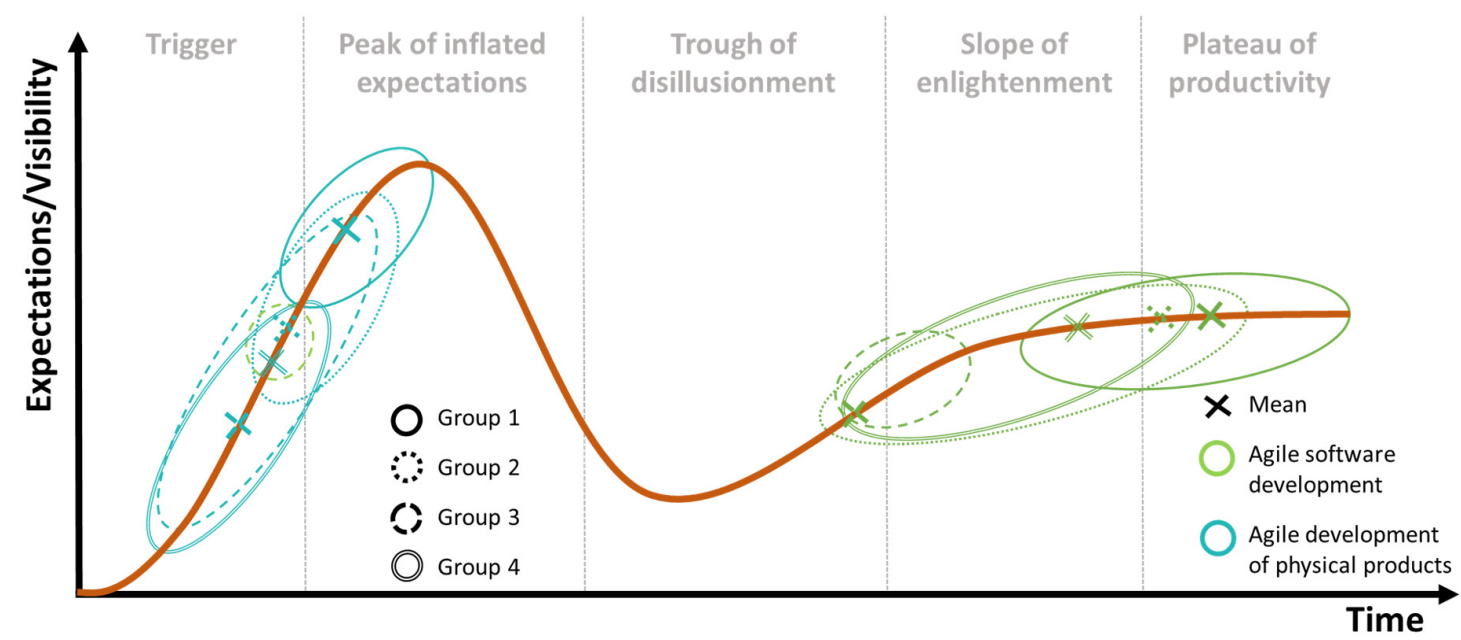

Figure 4. Gartner Hype Cycle applied to agile software development and agile development of physical products: Results of positioning during conference workshop 


\section{Discussion}

As Figure 4 shows, agile development of physical products is on the rise. The underlying concepts and its adaption to hardware seem to be immature. This insight is in line with the survey results, on the one hand. In fact, not all expectations can be realised. Having Gartner's Hype Cycle and the position of agile development of physical products in mind, frustration is inevitable. According to the survey results, it is likely that frustration will occur predominantly for project costs and time.

On the other hand, Figure 1, Figure 2, Figure 3 and Figure 4 is consistent with agility research. Firstly, the constraints of physicality, the set of challenges that occur in agile development of physical product only, are mostly unsolved, yet (Ovesen, 2012; Schmidt and Paetzold, 2016; Schmidt et al., 2017). Constraints of physicality, coined by Ovesen (2012), are not or at least not to this extent present in agile software development. This can be, for instance, the time and effort to build and test prototypes, which is much larger compared to agile software development as, for instance, efficient automation routines are oftentimes missing. This fact confirms that agile development of physical products is immature, yet.

Secondly, the position evaluation of agile software development correlates with the analysis of Janes and Succi (2012). By performing a Google Trends analysis, they derived that agile software development has reached the trough of disillusionment phase in about 2012. According to the workshop participants' assessment, agile software development is on the slope of enlightenment or even further now in 2017. In this light, Figure 4 is plausible.

Finally, Stelzmann (2011) also constructed a means-end diagram for agile development of physical products. Although his diagram is rough, consists of only few instances and does contain only single describing terms for each item, which leaves room for interpretation, his diagram is largely in line with those created in the workshop. Stelzmann (2011) argues that the first means-end instance provides possible points of intervention in order to become more agile. In the study at hand, they reflect the values mostly associated with agile development of physical products in terms of real benefits. Calling it "points of intervention" highlights the fact that companies necessarily need to start with working on communication, transparency, flexibility and reaction time to changes in order to increase the ability to survive in dynamic and ever-changing environments by means of agile approaches.

Furthermore, Stelzmann (2011) confirms that agile development of physical products is all about coping with "strong and frequent, foreseeable and unforeseeable changes in an efficient and effective manner" (Stelzmann, 2011, S. 135) in order to develop a successfully marketable product. For him, stakeholder satisfaction, job satisfaction, teamwork and risk reduction are complementary values that are nice to have. More importantly, agile development brings decentralized situational awareness, continuous improvement, the ability to react to changes, flexibility as well as efficiency and effectiveness to projects under dynamic circumstances. He calls those factors "sub-functions of agility" (Stelzmann, 2011, p. 135). This way of thinking can be taken as a starting point to refine and reflect the core of agile development.

The empirical survey confirms the academic definitions of agile development. Developing in an agile manner means to be able to deal with ever-changing project circumstance, to consider changes as opportunities to learn and improve, and to transform them to one's own benefit. In order to be aware of arising changes, the development project needs to be transparent. This, in turn, requires communicative and committed project staff. Self-organized teams and decentralized decision making fosters reaction time to changes, for that flexibility (e.g. in project activities or product) is mandatory. According to the investigation at hand, this seems to be at the very core of agile development.

Especially in light of the book "Scrum: The art of doing twice the work in half the time" (Sutherland, 2014), the survey results are contradicting and alarming. After presenting parts of the empirical survey results to the workshop participants, one developer responded:

"Your study is a killer! I hope that my boss will not see your results because he would kill our attempts to implement agile development in our department."

While in classical hierarchies top managers orient their actions according to KPI's, developers are less KPI-driven. Agile development does have value, which justifies the existence of agile approaches. 
Consequently, the study can be used as an instrument in companies to sharpen the perspective on agile development at all hierarchical levels, to reflect on the motivations why certain roles do want (and others do not want) to implement agile development and to learn how to utilize the idea of agility in product development effectively.

As shown in the boxplot in Figure 2, the value assessment seems to deviate a lot. On the one hand, this is due to the discrete Likert scale. On the other hand, the perceived value differs among various job positions and industries. Among the survey participants, about $19 \%$ are project managers, $18 \%$ managers, $17 \%$ heads of departments and $15 \%$ developers. Most of them originate from the mechanical and plant engineering industry (about 30\%), vehicle and traffic engineering industry (18\%) and electrical engineering and electronics industry (12\%). Especially large companies with more than $500 \mathrm{~m} €$ yearly $(47 \%)$ sales and more than 5,000 employees (45\%) took part.

However, the study at hand is limited by the measurability of value. In particular, measuring soft factors like improved communication, transparency, increased reaction time to changes and flexibility in an objective and quantitative way is very difficult. It might be possible to find proxy variables that measure the effects of those soft criteria. Then, nevertheless, it remains questionable, if and - if yes - to which degree the proxy variable does really cover the dimension to be evaluated. Although hard controlling KPI's are usually well measureable, we decided to ask for the participants' perception in all partial values to keep them comparable to each other.

\section{Summary, limitation and future work}

We conclude that agile development is not hyped in general (as it is indirectly argued by Janes and Succi (2012)). More specifically, according to our survey, agile development of physical products is hyped in hard controlling KPI's in particular. When implemented properly, agile development indeed improves soft factors like communication, reaction time to changes, flexibility, transparency and commitment. On several means to an end instances, it can contribute to hard controlling KPI's like reduced costs and project lead times. However, there is no evidence that agile development has positive effects on them in every case. Consequently, we strongly advise against implementing agile development of physical products into companies, if accelerating time-to-market and reducing project costs are the only motivation. Agile development does not per se make development projects faster, nor cheaper, but it makes it transparent and responsive to foreseen and unforeseen changes.

As many hard controlling KPI's are among the top expected benefits, this study is alarming. There is a real threat that companies have too high or false expectation of agile development, which will turn out to be wrong during implementation. Agile development is no silver bullet, although many consultancies try to market it as such. In terms of Gartner's Hype Cycle, agile development of physical product seems to be close to the peak of inflated expectation. The study at hand can serve as a sign of caution in order to prevent companies from misleading implementation intends. See Schmidt et al. (2018) for more empirical results from the corresponding survey.

For the future, research should focus on the real core of agile development. More studies are needed to clear up what agile development really is and what it is not. As agile development predominantly is a mindset that might interfere with national culture, the study at hand, thus, limits itself on Germany, Austria and Switzerland. However, studies in other cultural areas are meaningful.

\section{Acknowledgement}

We want to kindly thank everyone who participated in the online survey or the Agile Pep Minds 2017 workshop in Berlin. Especially, we want to thank Verein Deutscher Ingenieure e.V. (VDI) for supporting us in distributing the survey and We.Conect $\mathrm{GmbH}$ as organizer of the Agile Pep Minds conference for letting us utilize a world café session for scientific purposes.

\section{References}

Beck, K. (2000), Extreme Programming Explained: Embrace Change, Addison-Wesley.

Beck, K. Beedle, M., van Bennekum, A., Cockburn, A., Cunningham, W. et al. (2001), Manifesto for Agile

Software Development. [online] Available at: agilemanifesto.org (accessed 28.01.2018.) 
Böhmer, A., Beckmann, A. and Lindemann, U. (2015), “Open Innovation Ecosystem - Makerspaces within an Agile Innovation Process”, ISPIM Innovation Summit, Brisbane, Australia.

Chuang, S.W., Luor, T. and Lu, H.P. (2014), "Assessment of institutions, scholars, and contributions on agile software development (2001-2012)”, Journal of Systems and Software, Vol. 93, pp. 84-101. https://doi.org/10.1016/j.jss.2014.03.006

Conboy, K. (2009), “Agility from first principles: Reconstructing the concept of agility in information systems development”, Information Systems Research, Vol. 20 No. 3, pp. 329-354. https://doi.org/10.1287/isre.1090.0236

Cooper, R.G. (2014), “What's Next?: After Stage-Gate”, Research-Technology Management, Vol. 57 No. 1, pp. 20-31. https://doi.org/10.5437/08956308X5606963

Dingsøyr, T., Nerur, S., Balijepally, V. and Moe, N.B. (2012), “A decade of agile methodologies: Towards explaining agile software development”, Journal of Systems and Software, Vol. 85 No. 6, pp. 1213-1221. https://doi.org/10.1016/j.jss.2012.02.033

Gartner Inc. (2017), Research Methodologies: Gartner Hype Cycle. [online] Gartner Inc. Available at: https://www.gartner.com/technology/research/methodologies/hype-cycle.jsp (accessed 05.12.2017).

Hostettler, R. and Böhmer, A.I. (2017), "Reducing Uncertainty within Minimum Time and Resources", 23th International ICE Conference on Engineering, Technology and Innovation (ICE'17), Madeira, Portugal, June 27 - 29.

Janes, A. and Succi, G. (2012), "The dark side of agile software development", Proceedings of the ACM International Symposium on New Ideas, New Paradigms, and Reflections on Programming and Software, Tucson, Arizona, USA, pp. 215-227. https://doi.org/10.1145/2384592.2384612

Komus, A. and Kuberg, M. (2017), Abschlussbericht: Status Quo Agile 2016/2017 (für Studienteilnehmer). [online] Koblenz: University of Applied Sciences Koblenz, Available at: https:/www.gpmipma.de/fileadmin/user_upload/Know-How/studien/Studie_Agiles-PM_web.pdf.

Menold, J., Simpson, T.W. and Jablokow, K.W. (2016), "The Prototype for X Framework: Assessing the Impact on Desirability, Feasibility, and Viability of End Designs", ASME 2016 International Design Engineering Technical Conferences \& Computers and Infomation in Engineering Conference, August 21 - 24, pp.1-12.

Nerur, S. and Balijepally, V. (2007), "Theoretical reflections on agile development methodologies", Communications of the ACM, Vol. 50 No. 3, pp. 79-83. https://doi.org/10.1145/1226736.1226739

Nerur, S., Mahapatra, R. and Mangalaraj, G. (2005), "Challenges of Migrating to Agile Methodologies", Communications of the ACM, Vol. 48 No. 5, pp. 73-78. https://doi.org/10.1145/1060710.1060712

Ovesen, N. (2012), The Challenges of Becoming Agile: Implementing and Conducting SCRUM in Integrated Product Development, PhD thesis, Aalborg University.

Rodríguez, P., Markkula, J., Oivo, M. and Turula, K. (2012), "Survey on agile and lean usage in finnish software industry", Proceedings of the ACM-IEEE international symposium on Empirical software engineering and measurement - ESEM '12, pp.139. https://doi.org/10.1145/2372251.2372275

Schmidt, T.S., Chahin, A., Kößler, J. and Paetzold, K. (2017), "Agile Development and the Constraints of Physicality: A Network Theory-based Cause-and-Effect Analysis", 21st International Conference on Engineering Design, Vancouver, Canada.

Schmidt, T.S., Guaragni, F. and Paetzold, K. (2016), "Demerging agility, leanness, flexibility, reconfigurability and changeability: Towards a clear distinction”, 22th International ICE Conference on Engineering, Technology and Innovation (ICE'16). Trondheim, Norwegen, June 13 - 15.

Schmidt, T.S. and Paetzold, K. (2016), "Agilität als Alternative zu traditionellen Standards in der Entwicklung physischer Produkte: Chancen und Herausforderungen”, In: Krause, D., Paetzold, K. and Wartzack, S. (Eds.), Design for X (DfX) Symposium, TuTech Verlag, Hamburg, Germany, pp. 255-267.

Schmidt, T.S., Weiss, S. and Paetzold, K. (2018), Agile Development of Physical Products: An Empirical Study about Motivations, Potentials and Applicability. [online] University of the German Federal Armed Forces. Available at: http://www.unibw.de/produktentwicklung.

Stelzmann, E.S. (2011), Agile Systems Engineering: Eine Methodik zum besseren Umgang mit Veränderungen bei der Entwicklung komplexer Systeme, PhD thesis, Technische Universität Graz. 
Sutherland, J.V. (2014), Scrum: The art of doing twice the work in half the time, Crown Business, New York.

Version One (2016), 10th annual State of Agile Report. [online] VersionOne Inc. Available at: https://versionone.com/pdf/VersionOne-10th-Annual-State-of-Agile-Report.pdf.

We.Conect (2016), Agile Pep Minds 2016. [online] we.Conect. Available at: http://agile-pep-minds.de.

We.Conect (2017), Agile Pep Minds Konferenz: Teilnehmerprofil. [online] we.Conect. Available at: http://agile-pep-minds.de/de/teilnehmer/ (accessed 05.12.2017).

Tobias Sebastian Schmidt, M.Sc.

Bundeswehr University Munich, Technical Product Development

Werner-Heisenberg-Weg 39, 85577 Neubiberg, Germany

Email: tobias.schmidt@unibw.de 